\title{
From farm to fork: cultivation, postharvest and processing of strawberry in Japan
}

\author{
1,* Shamsudin, R., ${ }^{2}$ Hamzah, H.Z., ${ }^{3}$ Kawamura, S., ${ }^{4}$ Yasunaga, E. and \\ ${ }^{1}$ Kamarul Zaman, A.A. \\ ${ }^{1}$ Department of Process and Food Engineering, Faculty of Engineering, Universiti Putra Malaysia, 43400 \\ UPM Serdang, Selangor, Malaysia \\ ${ }^{2}$ School of Business and Economics, Universiti Putra Malaysia, 43400 UPM Serdang, Selangor, Malaysia \\ ${ }^{3}$ Laboratory of Agricultural and Food Process Engineering, Graduate School of Agricultural Science, \\ Hokkaido University, Hokkaido, Japan \\ ${ }^{4}$ Graduate School of Agricultural and Life Sciences, The University of Tokyo, Japan
}

\begin{abstract}
Article history:
Received: 2 May 2020

Received in revised form: 1 October 2020

Accepted: 1 April 2021

Available Online: 18 April 2021
\end{abstract}

Keywords:

Strawberry,

Processing,

Cultivation,

Japan,

Case study

DOI:

https://doi.org/10.26656/fr.2017.5(S1).033

\begin{abstract}
Strawberry cultivated in Japan widely known for its sweet and soft nature which regards as premium fruits in Japan. The objective of the present study was to give an overview of strawberry cultivation, and postharvest processing in selected manufacturers and farms in Nagano, and Hokkaido, Japan. The information was obtained through an interview session, and questionnaire distribution. Case study approach was used to obtain data. The cultivation of strawberries in Japan at the selected study area was mainly planted in the greenhouse under controlled temperature to maintain the quality and yield of strawberries. The strawberries in all the selected farm used manual grading process during the strawberry picking process. Processing of strawberries into other products was often done in small-scale by farmers and sold directly from the farm and distributed to other local seller and supermarket which portrayed "from farm to fork" practice. Strawberries processed into products such as jam, drinks and ingredients in bakery goods were labelled as premium products sold in special shops in Japan. Japan's Strawberries and strawberrybased products produced by the larger manufacturer were able to penetrate the Hong Kong, Malaysia and Thailand market.
\end{abstract}

\section{Introduction}

Strawberry or scientifically called Fragaria ananassa is popular among consumer worldwide due to its distinctive taste, unique appearance and nutritional benefit. Strawberry is a non-climacteric fruit, originated from temperate regions but, can also be cultivated under sub-tropical, and tropical regions (usually at higher altitude area which has lower temperature (Al-Madhagi et al., 2018; Muzaffa et al., 2018). Strawberry required a cultivation temperature of day and night ranging from 20 to $28^{\circ} \mathrm{C}$ and 12 to $18^{\circ} \mathrm{C}$ respectively (Abidin et al., 2018). Strawberries can be cultivated either sexually from the seed, or asexually through runners which grown from the mother plant (Rubinstein, 2015).

The main producers of strawberries are USA, Turkey, Spain, Egypt and Mexico, which USA leading the market with an approximate production of 4 million tonnes of strawberries annually (Muzaffar et al., 2018).
In Japan, strawberries are the third most valuable crops produce alongside rice and tomatoes, which Tochigi, Fukuoka and Kumamoto were the top 3 producers of strawberries (Ishikawa et al., 2018; Petlock and Sugimoto, 2015). In the early years, the cultivation of strawberries in Japan was done in an open field farm but changed to greenhouses (Petlock and Sugimoto, 2015). Strawberries can be cultivated either in soil or soilless system using a hydroponic method of the plantation (de Miranda et al., 2014). The cultivation of strawberries in Japan mainly use soil as growth medium under greenhouse plantations enable farmers to control the temperature, water, pest, disease and pollination of strawberries during cultivation, pre and post-harvest process(Petlock and Sugimoto, 2015).

Despite the highly nutritious composition of strawberries, the shelf-life of fresh strawberries is short due to the susceptibility to fungal spoilage, and highly 
perishable due to natural ripening process (Octavia and Choo, 2017; Muzaffar et al., 2018). Fresh strawberries stored at an average temperature of $5^{\circ} \mathrm{C}$ may last up to 13 days (Nicolau-Lapeña et al., 2019). Thus, a good pre and postharvest handling were required in maintaining the quality of fresh strawberries. Strawberries often process into other products such as jam, juice, dried fruits and as bakery products to lengthen the shelf-life of strawberries (Muzaffar et al., 2018). Japan's consumer prefers fresh strawberries, but 2 to $3 \%$ of strawberries often processed into confectionery products (Petlock and Sugimoto, 2015).

The present study intended to report the current cultivation, postharvest and processing techniques and practices of strawberries by the selected farms and manufacturers from a selected area in Japan. The cultivar, effect of farm area, manpower to production yields, processing technology, the product and market of end products were obtained through a questionnaire, site visit and interview.

\section{Methodology}

\subsection{Study area}

In this study, ten respondents from selected farms, and manufacturer from Nagano, and Hokkaido were selected. Nagano is located about $200 \mathrm{~km}$ from Tokyo, Japan (as shown in Figure 1) having a dry climate with low annual precipitation rates (Nagano Prefecture, 2013). Hokkaido Island is located in the north of Japan having extreme weather during the winter (Yamasaki, 2013; Morishita, 2014) which popular with winter variety strawberries.

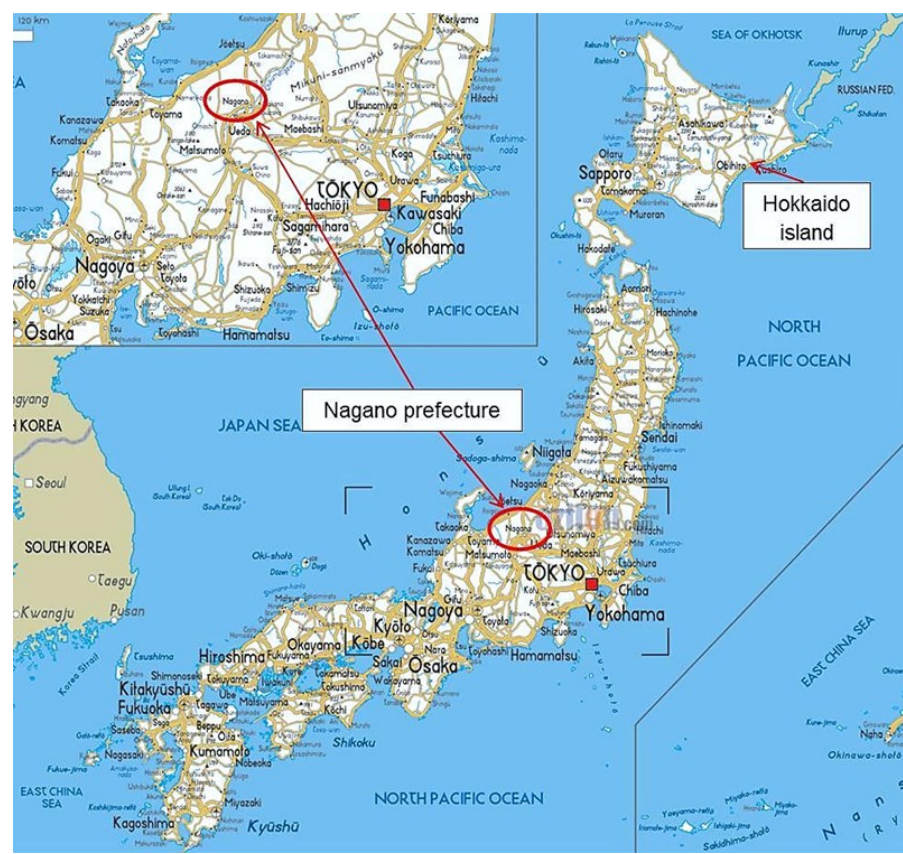

Figure 1. Selected area of study. Source: https:// www.ezilon.com/maps/asia/japan-road-maps.html

\subsection{Demographic information}

The demographic information of selected farms and manufacturer including the farm's area, employee, business operation, and establishment year were tabulated in Table 1. Based on the information obtained, farm 2, 3 and 4 produced their strawberry-based product to be sold directly to the consumer or visitor of their farm.

\subsection{Case study approach}

The results obtained in the present study were reported as a case study. The case study is an empirical evaluation of real-life conditions aiming to report comparable arguments or specific idea (Gabel et al., 2018). The information was obtained through the dissemination of the questionnaire, in-site visit and interview session with person-in-charge of selected study areas. The questionnaire includes both close-ended and open-ended questions covering the demographic information, cultivation techniques, processing of products and market of distributions. The respondents were picked randomly from the selected area of Nagano and Hokkaido. The obtained data then presented and discussed thoroughly with support from prior research available.

\section{Results and discussion}

\subsection{Cultivation of strawberry}

Based on the questionnaire distributed, in-site visit and interview, all farms selected in this study (Farm 1, $2,3,4,5,6,8$ and 10) using runners originated from the parental plants during cultivation of strawberries. The runners were placed approximately $10 \mathrm{~cm}$ away from each other. The spacing between plants is important for each plant to obtain optimum nutrients, moisture, light and space for growing (Shahzad et al., 2018). All farms used their own mother plant which the seedling was done using the potting technique, except Farm 8, that bought $70 \%$ of the mother plant from Hoishu as they were unable to fully breed their own mother plants. According to Hasan et al. (2011), the production of runner from the parental plant is effective at a day length of 12 to 15 hours of temperature ranging from 10 to $22.7^{\circ} \mathrm{C}$. The matured mother plant will produce runners through vegetative propagation that will produce new roots system (Kuchi and Sharavani, 2019). Farm 3 also uses the seedling method of strawberry's planting on their farm. The used of seed in strawberries planting reduce the risk of pathogen and viruses attack but much higher in cost, which stolons are preferred as it is more costeffective (Rubinstein, 2015). 
The cultivation of strawberries was done using soil in the bed system as indicated in Figure 2. Most of the farmer (Farm 2, 3, and 4) used coco-peat as the media for strawberries plantation. Coco-peat obtained from coconut able to retain water and increase the porosity of media which relatively improve the physical quality of strawberries produces, which is why it is often used in strawberries plantation worldwide (Hesami et al., 2012; Shamsudin et al., 2020). Farm 1 and 5 mixed coco-peat with rockwool and organic soil with rice husk respectively. Meanwhile, Farm 8 and 10 only use rockwool and organic soils respectively as the plantation media. The use of rockwool as media for strawberries plantation allowed a sustainable irrigation process (Depardieu et al., 2016). The use of organic soil meets the consumer demands of organic-based products with greater fruit quality but may increase the risk of microbial spoilage and pests (Shahzad et al., 2018).

\section{Soil / media used}

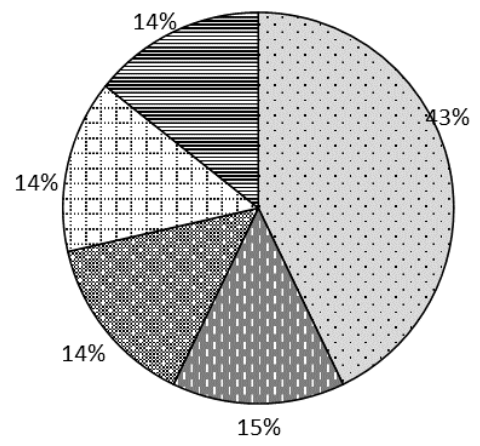

口Coco-peat

口Organic soil

Rockwool

GOrganic soil + Rice husk

目Coco-peat + rockwool

Figure 2. Soils or media used in strawberry plantation by selected farms in Japan

All selected farms in Japan in this study cultivate strawberries under greenhouse. Greenhouse cultivation under controlled environment enables all year production with constant yield, quality and better energy management in strawberries plantation (Miyoshi et al., 2013). Both Nagano and Hokkaido experience changes of temperature yearly due to the four-season climate in which the weather may become over humid and dry during summer and winter respectively (Shamsudin et al., 2020). The implementation of greenhouse cultivation over open field provides a solution for the climate limitation through the possibility of controlling the environmental parameters of temperature, humidity, air composition, and sunlight exposure for strawberries cultivation (Khoshnevisan et al., 2013). In the present study, more advance temperature controlling was observed in Farm 1 in Nagano, a research farm cultivating a summer cultivar of Shindai BS8-9. An automated temperature controller and, automated irrigation was set up on the farm. While Farm 6 from Hokkaido implied both open and greenhouse cultivation technique in which the farm area was let open during the planting period and closed during the flowering period under greenhouse. The flowering of strawberries usually appeared 3 months after planting which required higher temperature between 18 to $26^{\circ} \mathrm{C}$ (Rubinstein, 2015).

Other quality management in the cultivation of strawberries is the use of fertilizer and pesticide. Based on Figure 3, Farm 1 used both chemical and organic fertilizer on their farm. Farm 2, 3, 8, and 10 used chemical-based fertilizer and pesticide, while Farm 4, 5 and 6 used the organic fertilizer and pesticide. Fertilizer was added to the plants through the irrigation process directly to the soils for all studied farms. The addition of fertilizer through the fertigation process promotes the slow release of the macro and micronutrients needed for the growth of strawberries (Nestb and Guéry, 2017). The used of pesticide in strawberries cultivation is unavoidable as pathogenic and spoilage microorganism carried by the pests may result in lower yield and quality of fruits. Botrytis cinera is the most common fungus attacking strawberries both during pre and postharvest resulted in fruit softening and the appearance of gray mould on fruits surfaces (Feliziani and Romanazzi, 2016).

Fertilizer and pesticide used by farm

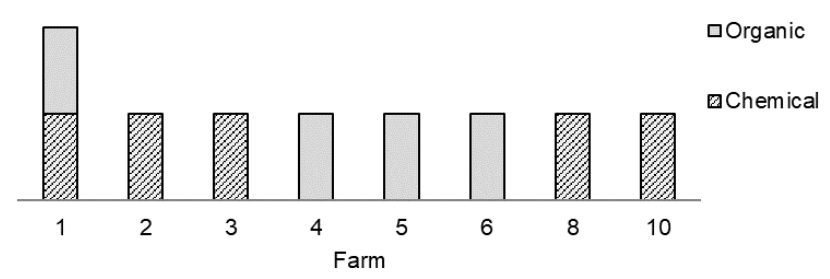

Figure 3. Fertilizer and pesticides used by farmers

\subsection{Post-harvest of strawberries}

The variety of strawberries in Japan varies according to the cultivation area, farms and climate suitability. Winter type varieties planted by selected farmers include Akiheme, Tochiotome, Bennihoppe, Kentara Houka, Yutshuboshi, and Shinku no misuza. In the meanwhile, Shindai BS8-9, Kaori Noh, Shuzu Akane, Karuizawa, and Aoh Akane were the summer variety planted by selected farmers from Nagano and Hokkaido. From Figure 4, Farm 3, and 4 cultivated different varieties of strawberries including both the winter and summer variety to ensure the sustainability of the produce both for local and export, as the farm also processed their strawberries into products. Farm 8 also cultivates different varieties in their farm to meet the market demands as they export their fresh-strawberry to Hong Kong.

The matured strawberries were harvested manually 
by all farms to ensure only high-quality fruits were picked. The manual picking also intended to minimize bruising or physical damage on fruits as strawberries is highly perishable (Petlock and Sugimoto, 2015). The fresh strawberries then, manually graded before distribution. The grading was done based on shapes, colour and weight. The shape of strawberries varies according to the variety planted by the farmer. There were approximately 9 types pf strawberry shapes which are reinform, conical, cordate, ovoid, cylindrical, rhomboid, obloid, globose and wedge (Ishikawa et al., 2018). Harvested strawberries can be stored within 5 to 9 days in cool temperature above $0^{\circ} \mathrm{C}$ depending on ripeness upon harvesting (Rubinstein, 2015). No sanitization process either with water or chemical sanitiser was done to fresh strawberries by all the studied farms as such practice may affect the texture and inhibit bacterial growth especially moulds if not properly dried afterwards.

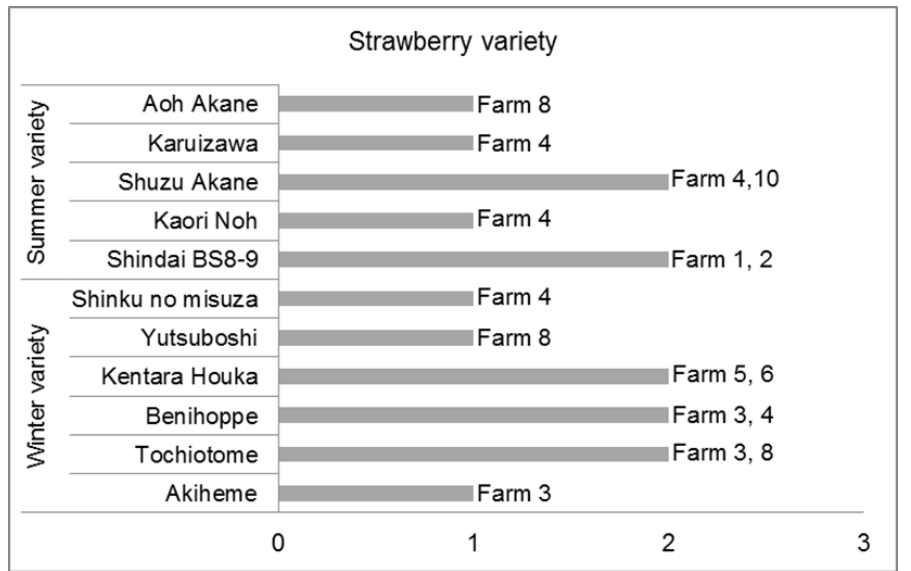

Figure 4. Varieties of strawberry cultivated in selected farms in Nagano and Hokkaido, Japan

Fresh strawberry then carefully packed into clamshell container intended for direct selling, while corrugated box was used for wholesale and export market of fresh-strawberries. Farm 3 distributed their fresh strawberries to Kyoto prefecture and exported to Thailand, Mongolia, and Hong Kong. Farm 4 also, exports their strawberries to Thailand via airport distribution. Meanwhile, Farm 8 distributed their fresh produce within the country to Tokyo through Kansai airport. Styrofoam was often added on top of the packaging material to protect the strawberries from any shocking damages during transportation (Petlock and Sugimoto, 2015).

\subsection{Processing of strawberry-based product}

Based on Table 1, Farm 2, 3, and 4 processed their strawberry into other products in small-scale and sold the products only within their farm area with nearby supermarkets and specialty shops. The results obtained in Figure 5 shows that confectioneries products such as jam, chocolate, and sweets top the market demands of strawberry based product in the selected study area in Japan. Manufactures 7, and 9 produced strawberry-based products on a larger scale. Manufacturer 9 is one of the popular food processors in Japan which produced strawberry based confectionery (includes chocolate, strawberry sweets and biscuits) and bakery products include cookies, muffin and cakes. Their products were not only for the local consumption but also for the export market of Hong Kong and Malaysia. In the processing of strawberry into other goods with longer shelf-life, the quality of products was taken care of starting from the raw ingredients. Fresh strawberry used was obtained directly from the farm and manually graded before processing. Manufacturer 9 obtained their raw material from a farm located $15 \mathrm{~km}$ away and transported via land transportation.

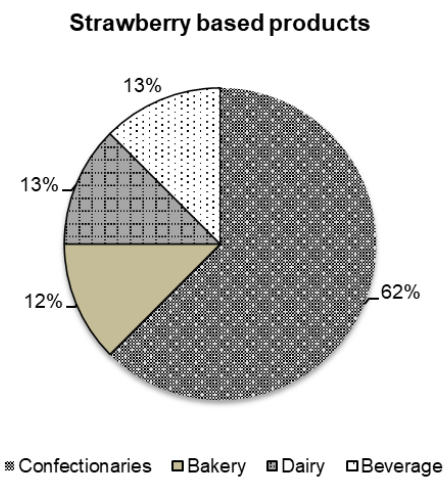

Figure 5. Strawberry based products

Strawberry jam is the main and best-selling product produced by manufacturer 7 . Jam is a product with at least $45 \%$ of fruits contents with total soluble solid approximately $45^{\circ} \mathrm{C}$ (Mohd Naeem et al., 2017). The processing of strawberry jam was done using conventional heating method. In conventional jam processing, fruits will be crushed after washing and heated at temperature $90^{\circ} \mathrm{C}$ and below for a period (Ismail et al., 2018). The jam was sold in Sapporo through the small and large retailer, supermarket and sold online through an e-commerce website. Farm 2, and 3 also produced jam as one of their side products sold directly to the customer who visited their farm. The jams were packed in a glass bottle to illustrate the premium quality of products produced.

Strawberry cakes and sweets are popular among woman and children in Japan (Masaki, 2010) which made it as one of the popular strawberry-based products sold locally. The processing of strawberry cakes or other bakery products were often made fresh and directly sold in specialty shops or cake shops. Strawberries are added as one of the flavouring and colouring ingredients or for decoration purposes. The bright red colour of strawberry and distinctive aroma attract consumer interest which influenced the processing company to produce a wide 


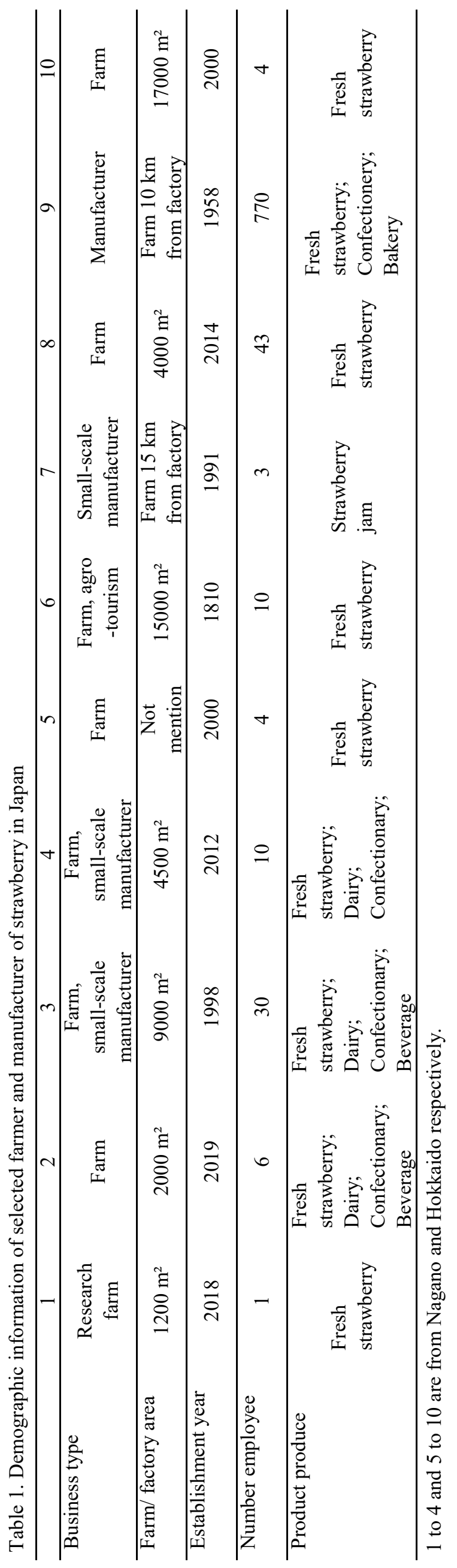


variety of strawberry products (Gössinger et al., 2009).

\section{Conclusion}

The present study showed that the cultivation, postharvest processing of strawberries in a selected area in Japan was still done in small-scale. However, in order to meet the market demands of all year round, farmers cultivated multiple varieties of strawberries to ensure the consumer can have the products both during summer and winter season. Greenhouse cultivation enabled the farmers to have control of their strawberry qualities even in extreme weather conditions. Strawberry based products produced in small-scale by the farmers were also sold as premium products not intended to increase their gross income.

\section{Conflict of interest}

All authors did not have any conflict of interest.

\section{Acknowledgement}

The authors express their gratitude to the Sumitomo Foundation Fiscal 2018 Grant for Japan-Related Research Projects for providing financial support and Universiti Putra Malaysia for the technical support to conduct this research work. The authors would also like to acknowledge all farmers and manufacturers from Cameron Highlands, Nagano and Hokkaido involved in this research.

\section{References}

Al-Madhagi, I.A.H., Al-Munibary, M. and Al-Doubibi, M. (2018). Effect of Chilling and Accumulative Photo-Thermal Units on Flowering of Strawberry (Fragaria $\times$ ananassa Duch.). Journal of Horticultural Research, 26(2), 25-35. https:// doi.org/10.2478/johr-2018-0013

Abidin, M.A.Z., Ahmad, D., Suraidi, A.S. and Pahang, J.T. (2018). The influence of root zone temperature manipulation on strawberry yields in tropics. In Saian, R. and Abbas, M.A. (Eds.) Proceedings of the Second International Conference on the Future of ASEAN (ICoFA) 2017 - Volume 2, p. 695-703. Singapore: Springer. https://doi.org/10.1007/978-981 $-10-8471-3$

de Miranda, F.R., da Silva, V.B., Santos, F.S.R.dos, Rossetti, A.G. and da Silva, C.D.F.B. (2014). Production of strawberry cultivars in closed hydroponic systems and coconut fibre substrate. Revista Ciencia Agronomica, 45(4), 833-841. https://doi.org/10.1590/s1806-66902014000400022

Depardieu, C., Prémont, V., Boily, C. and Caron, J.
(2016). Sawdust and bark-based substrates for soilless strawberry production: Irrigation and electrical conductivity management. PLOS ONE, 11 (4), 1-20. https://doi.org/10.1371/ journal.pone.0154104

Feliziani, E. and Romanazzi, G. (2016). Postharvest decay of strawberry fruit: Etiology, epidemiology and disease management. Journal of Berry Research, 6(1), 47-63. https://doi.org/10.3233/JBR-150113

Gabel, V., Home, R., Stöckli, S., Meier, M., Stolze, M. and Köpke, U. (2018). Evaluating on-farm biodiversity: A comparison of assessment methods. Sustainability (Switzerland), 10(12), 1-14. https:// doi.org/10.3390/su10124812

Gössinger, M., Moritz, S., Hermes, M., Wendelin, S., Scherbichler, H., Halbwirth, H., Stich, K. and Berghofer, E. (2009). Effects of processing parameters on colour stability of strawberry nectar from puree. Journal of Food Engineering, 90(2), 171 -178. https://doi.org/10.1016/j.jfoodeng.2008.06.018

Hasan, S.M.Z., Al-madhagi, I., Ahmad, A. and Yusoff, A. (2011). Effect of Photoperiod on Propagation of Strawberry ( Fragaria x ananassa Duch). Journal of Horticulture and Forestry, 3(8), 259-253.

Hesami, A., Khorami, S.S., Amini, F. and Kashkooli, A.B. (2012). Date-peat as an alternative in hydroponic strawberry production. African Journal of Agricultural Research, 7(23), 3453-3458. https:// doi.org/10.5897/AJAR11.1933

Ishikawa, T., Hayashi, A., Nagamatsu, S., Kyutoku, Y., Dan, I., Wada, T., Oku, K., Saeki, Y., Uto, T., Tanabata, T., Isobe, S. and Kochi, N. (2018). Classification of strawberry fruit shape by machine learning. International Archives of the Photogrammetry, Remote Sensing and Spatial Information Sciences - ISPRS Archives, 42(2), 463470. https://doi.org/10.5194/isprs-archives-XLII-2463-2018

Ismail, N.A.M., Abdullah, N. and Muhammad, N. (2018). Effect of microwave-assisted processing on quality characteristics of pineapple jam. Journal of Advanced Research in Fluid Mechanics and Thermal Sciences, 42(1), 24-30.

Khoshnevisan, B., Rafiee, S. and Mousazadeh, H. (2013). Environmental impact assessment of open field and greenhouse strawberry production. European Journal of Agronomy, 50, 29-37. https:// doi.org/10.1016/j.eja.2013.05.003

Kuchi, V.S. and Sharavani, C.S.R. (2019). Fruit Physiology and Postharvest Management of Strawberry. In Asao, T. and Asaduzzamn, M. (Eds.) Strawberry - Pre- and Post-Harvest Management 
Techniques for Higher Fruit Quality. IntechOpen Ebook. https://doi.org/10.5772/intechopen.84205

Masaki, T. (2010). The cultivation of strawberry in Japan. Safe Vegetable Promotion Product in Benguet. Japan: Nagano Prefecture.

Miyoshi, Y., Hidaka, K., Okayasu, T., Hirano, O., Yasutake, D. and Kitano, M. (2013). Approach to local environment control for stable production of strawberry. IFAC Proceedings Volumes (IFACPapersOnline), 1(PART 1), 6-9. https:// doi.org/10.3182/20130327-3-jp-3017.00016

Mohd Naeem, M.N., Mohd Fairulnizal, M.N., Norhayati, M.K., Zaiton, A., Norliza, A.H., Wan Syuriahti, W.Z., Mohd Azerulazree, J., Aswir, A.R. and Rusidah, S. (2017). The nutritional composition of fruit jams in the Malaysian market. Journal of the Saudi Society of Agricultural Sciences, 16(1), 89-96. https://doi.org/10.1016/j.jssas.2015.03.002

Morishita, M. (2014). The Status of Strawberry Breeding and Cultivation in Japan. Acta Horticulturae, 1049, 125-132.

https://doi.org/10.17660/

ActaHortic.2014.1049.10

Muzaffar, H., Rouf, A., Kanojia, V., Muzaffar, Z. and Noor, F. (2018). Dehydration of Strawberry-A Review. International Journal of Current Microbiology and Applied Sciences, 7(1), 12161224. https://doi.org/10.20546/ijcmas.2018.701.148

Nagano Prefecture. (2013). Retrieved from http:// www.pref.nagano.lg.jp/kokusai/government/english/ index.html

Nestb, R. and Guéry, S. (2017). Balanced fertigation and improved sustainability of June bearing strawberry cultivated three years in open polytunnel. Journal of Berry Research, 7(3), 203-216. https:// doi.org/10.3233/JBR-170157

Nicolau-Lapeña, I., Abadias, M., Bobo, G., AguilóAguayo, I., Lafarga, T. and Viñas, I. (2019). Strawberry sanitization by peracetic acid washing and its effect on fruit quality. Food Microbiology, 83 (April), 159-166. https://doi.org/10.1016/ j.fm.2019.05.004

Octavia, L. and Choo, W.S. (2017). Folate, ascorbic acid, anthocyanin and colour changes in strawberry (Fragaria $\times$ annanasa) during refrigerated storage. LWT - Food Science and Technology, 86, 652-659. https://doi.org/10.1016/j.1wt.2017.08.049

Petlock, B. and Sugimoto, N. (2015). Japan. Strawberry market situation. Report No.: JA5023. USA: USDA Foreign Agricultural Service

Rubinstein, J. (2015). Fragaria x ananassa: Past, Present and Future Production of the Modern Strawberry. Retrieved from University of Minnesota website: https://conservancy.umn.edu/bitstream/ handle/11299/175838/Jared Rubinstein Strawberry.pdf? sequence $=1$ andisAllowed $=\mathrm{y}$

Shahzad, U., Ijaz, M., Noor, N., Shahjahan, M., Hassan, Z., Kahn, A.A. and Calica, P. (2018). Variations in growing media and plant spacing for the improved production of strawberry (Fragaria ananassa cv. Chandler). Philippine Journal of Science, 147(4), 705-713.

Shamsudin, R., Hamzah, H.Z., Shuso, K., Yasunaga, E. and Zaman, A.A.K. (2020). A Comparison of Strawberry Cultivation: Case Study of Selected Farms in Malaysia and Japan. International Journal of Academic Research in Business and Social Sciences, 10(1), 232-250. https://doi.org/10.6007/ IJARBSS/v10-i1/6847

Yamasaki, A. (2013). Recent Progress of Strawberry Year-round Production Technology in Japan. Japan Agricultural Research Quarterly, 47(1), 37-42. https://doi.org/10.6090/jarq.47.37 